\title{
BMJ Open Quality of care for people with multimorbidity: a focus group study with patients and their relatives
}

\author{
Nadine Janis Pohontsch (10) , Josefine Schulze, ${ }^{1}$ Charlotte Hoeflich, ${ }^{1}$ \\ Katharina Glassen, ${ }^{2}$ Amanda Breckner, ${ }^{2}$ Joachim Szecsenyi, ${ }^{2}$ Dagmar Lühmann, ${ }^{1}$ \\ Martin Scherer ${ }^{1}$
}

To cite: Pohontsch NJ, Schulze J, Hoeflich C, et al. Quality of care for people with multimorbidity: a focus group study with patients and their relatives. BMJ Open 2021;11:e047025. doi:10.1136/ bmjopen-2020-047025

- Prepublication history and additional supplemental material for this paper are available online. To view these files, please visit the journal online. To view these files, please visit the journal online (http://dx.doi org/10.1136/bmjopen-2020047025).

Received 16 November 2020 Accepted 12 May 2021

Check for updates

(C) Author(s) (or their employer(s)) 2021. Re-use permitted under CC BY-NC. No commercial re-use. See rights and permissions. Published by BMJ.

${ }^{1}$ Department of General Practice and Primary Care, University

Medical Center Hamburg-

Eppendorf, Hamburg, Hamburg, Germany

${ }^{2}$ Department of General Practice and Health Services Research,

University Hospital Heidelberg,

Heidelberg, Baden-Württemberg, Germany

Correspondence to

Nadine Janis Pohontsch;

n.pohontsch@uke.de

\section{ABSTRACT}

Background Prevalence of people with multimorbidity rises. Multimorbidity constitutes a challenge to the healthcare system, and treatment of patients with multimorbidity is prone to high-quality variations. Currently, no set of quality indicators (QIs) exists to assess quality of care, let alone incorporating the patient perspective. We therefore aim to identify aspects of quality of care relevant to the patients' perspective and match them to a literature-based set of Qls.

Methods We conducted eight focus groups with patients with multimorbidity and three focus groups with patients' relatives using a semistructured guide. Data were analysed using Kuckartz's qualitative content analysis. We derived deductive categories from the literature, added inductive categories (new quality aspects) and translated them into QI.

Results We created four new Qls based on the quality aspects relevant to patients/relatives. Two Qls (patient education/self-management, regular updates of medication plans) were consented by an expert panel, while two others were not (periodical check-ups, general practitioner-coordinated care). Half of the literaturebased Qls, for example, assessment of biopsychosocial support needs, were supported by participants' accounts, while more technical domains regarding assessment and treatment regimens were not addressed in the focus groups.

Conclusion We show that focus groups with patients and relatives adding relevant aspects in QI development should be incorporated by default in QI development processes and constitute a reasonable addition to traditional QI development. Our QI set constitutes a framework for assessing the quality of care in the German healthcare system. It will facilitate implementation of treatment standards and increase the use of existing guidelines, hereby helping to reduce overuse, underuse and misuse of healthcare resources in the treatment of patients with multimorbidity.

Trial registration number German clinical trials registry (DRKS00015718), Pre-Results.

\section{INTRODUCTION}

Our society is ageing and higher life expectancy is associated with higher rates of chronic diseases. Care for patients with multimorbidity
Strengths and limitations of this study

- Affected patients and their relatives (who often function as informal caregiver) were interviewed in the focus groups.

- Focus group participants from two differently structured regions in Germany representing a wide spectrum of combinations of different diseases were queried.

- Focus groups with patients and their relatives (asking about positive and negative experiences with care) seem to be an effective tool to identify quality aspects relevant to quality indicator development.

is likely to evolve into one of our most prominent challenges in the future. ${ }^{1}{ }^{2}$ Multimorbidity is strongly linked to functional limitations, lower quality of life and increase in healthcare utilisation, costs and higher mortality. ${ }^{34}$ Care for patients with multimorbidity is very complex ${ }^{5}$ and therefore prone to deficits in quality and major (unintended) interindividual differences regarding the impact of illness and carer performance. ${ }^{6-9}$ Multimorbidity creates many challenges to general practitioners (GPs) and affected patients alike, for example, (too) short consultation times, polypharmacy, increased healthcare utilisation, high treatment burden and self-management requirements as well as psychological distress. ${ }^{10} 11$ Several decades of research and discussion have provided us with suggestions for management approaches in primary care to better address the needs of this patient group, inter alia, the Chronic

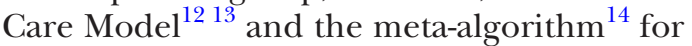
treating patients with multimorbidity.

Generic standards for high quality of care are hard to define due to the infinite number of possible (combinations of) medical problems in patients with multimorbidity. Evidence-based standards relevant to patients with multimorbidity are urgently 
needed, because single-disease clinical guidelines are for several reasons often inadequate for this patient population. ${ }^{10}$ As long as the current state of healthcare cannot be mapped systematically, for example, by using a set of quality indicators (QIs) specific for multimorbidity, it remains impossible to compare the effects of interventions and healthcare models to optimise quality or to identify sectors, regions or healthcare providers needing improvement.

In Germany, the first point of contact in the healthcare system for people who fall ill is usually a GP. GPs are usually licensed to provide care on the basis of contracts with the statutory health insurance (SHI) and are members of the corresponding association of SHI doctors. The SHI covers about $90 \%$ of Germany's residents and is complemented by a private health insurance system. German GPs have usually completed 5 years of further training to be allowed to call themselves specialists in general practice/primary care. Patients are free to consult any GP unless they choose to enrol themselves in a GP contract ('Hausarztzentrierte Versorgung'). The contractually defined GP-coordinated care further strengthens the role of the GPs as guides and coordinators for the healthcare of their patients. ${ }^{15}$ GPs refer patients to outpatient specialists or hospitals when further or specialised care is needed. There are more than 100 different types of patient record management software ${ }^{16}$ and usually the patient records of different doctors are not linked, which means that their communication and coordination often rely on (referral/discharge) letters and patients' reports.

Taking the patients' perspective into consideration is even more relevant when dealing with patients with multimorbidity. Every decision made concerning risks and benefits of treatments and interventions has to be weighed against individual impairments, comorbidities and gain in subjective quality of life. ${ }^{14}$ Prioritisation must take the whole range of biopsychosocial complexities into account and follow principles of patient-centred clinical management and decision-making. Views on high-quality healthcare often differ between patients and their healthcare providers. ${ }^{17} 18$ For example, quality of care seems to be higher when process or intermediate outcome indicators are measured and lower when patient-reported experiences of care are reviewed. ${ }^{18}$ Therefore, patients ${ }^{19}$ can and must be involved in guideline and QI development. ${ }^{20-23}$ Studies show that this is not often the case ${ }^{21}$ even though approaches to patient involvement in QI development, for example, focus groups, exist and are considered to be of high value. ${ }^{20}$

The MULTIqual Project aims for the development of a QI set which can be used to evaluate the current state of healthcare provided for patients with multimorbidity and to promote the implementation of treatment standards for future care. We conducted focus groups with patients with multimorbidity and their relatives to validate and amend a literature-based and expert consensus-based set of QIs by qualitatively surveying their views on healthcare quality.

\section{METHODS}

The MULTIqual Project is a multicentre mixed-methods project comprising a systematic literature review, focus groups, a two-stage expert consensus process, and a quantitative survey with patients with multimorbidity and GPs. Following the Consolidated criteria for Reporting Qualitative research, ${ }^{24}$ this paper presents the results of focus groups with patients with multimorbidity and their relatives conducted in Hamburg and Heidelberg and of the expert consensus on the qualitatively derived QIs. The details of the systematic literature review, expert panel, consensus process and QI development process are not directly relevant to the work presented here, but can support the understanding of the whole project. A summary of the process can be found in online supplemental file 1 . An extensive description will be presented elsewhere (manuscript in preparation).

\section{Participant selection and recruitment}

We randomly selected the GPs from the register of SHIaccredited doctors of the city districts or within a radius of $25 \mathrm{~km}$ around the two study centres, respectively. We invited the selected GPs to participate in our study and informed them in detail about the project if they were interested. Participating GPs were asked to recruit patients aged 65 years and above with three or more chronic conditions who attended the practice at least once in the last 3 months. Patients with multimorbidity willing to participate were asked to invite close relatives to take part in the study as well. Exclusion criteria were insufficient knowledge of the German language and inability to give informed consent. Patients received an invitation containing study information, a response sheet and a reply envelope. Participants received an allowance of $€ 30$ plus a reimbursement of travel expenses. Participants gave written informed consent for the focus groups to be recorded, transcribed and the data being published anonymously.

\section{Focus group guide}

Guide development was based on the literature review $\left(\mathrm{eg},{ }^{25}\right)$ and the research questions outlined above. As lay persons mostly relate to implicit experiential knowledge when defining quality criteria $\left(\mathrm{eg},{ }^{26}{ }^{27}\right)$, we chose to question our focus group participants about their own positive and negative experiences with primary healthcare, changes in their healthcare needs and experiences due to multimorbidity, and their vision of ideal primary care for people like them (see online supplemental file 2 for 'patients' focus group guide'). With patients' relatives, the same topics were discussed in respect of the associated patient with multimorbidity (see online supplemental file 3 for 'relatives' focus group guide').

\section{Data collection}

Either JS, CH, AB or KG had spoken to the participants on the phone, but had no other relationship with them. In December 2018 and January 2019, we conducted 
eight focus groups with patients with multimorbidity (city $\mathrm{A}=3$, city $\mathrm{B}=5$ ) and three focus groups with patients' relatives $(\mathrm{A}=1, \mathrm{~B}=2)$ using the semistructured guides described above. Two moderators facilitated the focus groups (NJP, JS, KG, AB, CH and TKl, respectively) which lasted about 2 hours. Discussions were digitally recorded and transcribed verbatim by a trained research assistant following designated transcription rules. Accuracy of the transcripts was checked by the respective moderators. In order to protect the focus group participants' identity, names and other identifying details were changed during transcription.

\section{Data analysis}

Data were analysed using the qualitative content analysis approach described by Kuckartz, ${ }^{28}$ following a realistic paradigm. ${ }^{29}$ Coders (NJP, CH and JS) read all transcripts to familiarise themselves with the data. Transcripts were broken down into fragments adopting different sizes ranging from part of a sentence to one or more paragraphs in relation to the segment length needed to understand the content and context of the relevant accounts. We created deductive codes representing the aspects of quality described in the literature-based QI set and selected by the expert panel and inductive codes when new aspects of quality emerged from the data (see below). We then subjected all transcripts to a second round of coding by a different coder. Coding was carried out with constant discussions between the three coders about the coded text passages and assigned codes. To ensure intersubjective reproducibility and comprehensibility, ${ }^{30}$ the results were presented to and discussed with the interdisciplinary workgroup 'qualitative methods' and the coauthors DL (postdoctorate, MD) and MS (professor, MD). Data were managed using MAXQDA V.11 (Verbi).

\section{Identification of additional patient-relevant quality aspects and expert rating of deduced QI}

We aimed to supplement the preliminary QI set extracted from a systematic literature review by QI based on patientrelevant quality aspects derived from the focus group data. A multidisciplinary research team (NJP, CH, KG, AB and JS) allocated subjectively important quality aspects from patients' and their relatives' views to the preliminary set of QIs based on the literature review and identified important additional quality aspects where needed. Afterwards, the research team transformed the additionally identified quality aspects into QI (including description, numerator, denominator, exclusion criteria, etc). These QIs were presented by NJP to an expert panel during an in-person meeting. The expert panel consisted of representatives of primary care, nursing, practice management, quality research methodology, social work, physical therapy, geriatrics, clinical pharmacology, social medicine and patient representatives. The in-person meeting took place on 1 February 2019. During the meeting, NJP presented the focus group material-based new QI to the expert panel. After a rating of relevance, strength of evidence and their potential for undesirable effects, the expert panel voted for keeping or rejecting the QI deduced from the focus group material via nominal group technique.

\section{Patient and public involvement}

Patients were involved in the recruitment of focus group participants (viz. their relatives). Patient representatives and representatives of relevant fields (see above) were involved in the rating and selection of QI. Apart from that, there was no patient or public involvement in the study.

\section{Researcher characteristics}

Researchers' characteristics, beliefs and assumption influence qualitative research and data interpretation. NJP (q): post-doc psychologist, experienced qualitative researcher (patient involvement in QI development, healthcare research focusing on general practice); JS (ㅇ): psychologist/junior scientist; $\mathrm{CH}$ (ㅇ): medical student; $\mathrm{AB}($ ( $)$ : junior scientist, M A Health Information Management; DL (ㅇ), KG (ㅇ), JSz (ठ⿱), MS (đ): medical professionals, experienced post-doc researchers in the field of general practice and QI development.

\section{RESULTS}

\section{Participants' characteristics}

We included 29 female and 18 male patients aged 65-84 years as well as three female and six male relatives (five spouses/four children) aged 49-78 years in five patient groups, and three relatives groups, respectively. Nine registered volunteers did not take part, with $n=3$ due to acute health problems and $n=6$ due to organisational difficulties.

Focus group-based additional quality aspects included into the QI set after the expert panel rating

Two focus group-based quality aspects were finally supported by the expert panel and included in the QI set.

\section{Patient education/self-management}

Patients consider it very helpful to be informed about their diseases and possible (self-) treatment and management strategies (for example, nutrition counselling). Daily disease management can be supported by specific information on self-management strategies, training in disease-related competencies (for example, measuring the INR (International Normalized Ratio) value), addressing coping strategies and provision of knowledge for the patient.

I took part in a course in [city] and have been monitoring my 'Quick' [prothrombin time] myself for over 20 years and I have a book and also keep a record. And I always took it with me to the hospitals and the doctors were amazed that they could see exactly how I did it and how I tested my 'Quick'. [...] And I always write it down and then I 
dose the medication myself. No, I am still grateful to the doctor for giving me the tip that I can do the course how to measure my 'Quick' on my own [...]. (city B, patient focus group A, paragraph 162-166)

\section{Regular updates of medication plan}

Patients report to have been provided with medication plans and consider it very important for them to be up to date especially when taking a high number of different medications or when medication is prescribed by specialists. Some patients always have copies of their medication plan at hand in case of an emergency and it would be considered helpful if this plan was accessible electronically on the health insurance card.

This is also from the GP, right? It's a medication plan. So you know when to take it and so on. One should know that. But also that you can show it, if someone asks: 'What are you taking?' Oh god, yes, what am I taking? What's it called again? It just changed again, hasn't it? Well, I know it, but it's also good for the other doctors if they have something printed and to be able to see exactly what she needs, what she takes, how often and when [...]. So, it is very pleasant when GPs do something like that. Gives you a certain amount of security. (city A, patient focus group B, paragraph 251-253)

\section{Focus group-based additional quality aspects not included} into the QI set after the expert panel rating

Two other indicators were not supported by the expert panel and not included in the final QI set.

\section{Regular check-ups}

Patients with chronic diseases see a need for regular check-ups as it would allow for early detection of health deterioration and they know these procedures from the disease management programmes, for example, for diabetes or chronic obstructive pulmonary disease (COPD). They value the regular contact with the GP at fixed appointments.

[...] if you take these medications regularly and then say: "We'll have a general check-up once every two years" - I think that's not enough. I think it should be every year. The status should be checked once in a while, if I'm taking these pills regularly. (city A, patient focus group C, paragraph 97)

\section{GP-coordinated care}

Patients appreciate the GPs to coordinate their care which involves, for example, writing referral letters for specialist visits (and the GP receiving medical reports), having a network of specialists at hand, planning preventive measures, and keeping track of medications and their interactions and side effects. Patients who describe their relationship with their GP as trusting want all information on their healthcare to converge at their GPs' practice.

[...] when the diagnoses are made and the GPs know what's going on, then they should actually act as a control center and have the possibility to coordinate everything. (city A, patient focus group A, paragraph 264)

That's a given in our practice. He always wants to give you referrals because he wants to have doctor's letters. Otherwise he says he doesn't have an overview. And I think that's very, very good. (city B, relatives' focus group A, paragraph 66)

\section{Literature-based quality aspects supported by focus groups}

Table 1 gives an overview of quality aspects identified in the literature review and supported by both focus groups and expert consensus and shows supporting quotes from the focus groups. Descriptions of categories shown in table 1 follow below.

\section{Assessment of biopsychosocial support needs}

Patients expressed a need for the GP to have a holistic view on the patient's health problems and needs. They underlined the importance of not only seeing and treating physical symptoms, but also the overall picture of medical and psychosocial aspects of the patient's situation. They consider it important for the GP to have at least basic information on the patient's background and personal history. Sometimes house calls can be necessary for a realistic judgement on biopsychosocial support needs, for example, for elderly people with beginning dementia.

\section{Involving partners, family and caregivers}

Relatives of people with multimorbidity often appreciate the GPs' willingness to communicate with them and support them in the process of giving care. Support and advice are often desperately needed by informal caregivers of persons with multimorbidity, especially if dementia is an issue. GP's awareness of informal caregivers' problems and concerns is important and could, for example, be addressed by offering consultation hours for relatives and other informal caregivers.

Shared decision-making and mutual agreement on treatment goals Shared decision-making to find a customised treatment approach for individual patients is highly appreciated by the focus group participants. Communicating, informing and deciding on treatment regimens and goals on a par with the patient are seen as essential for increasing adherence and patient satisfaction. Patients value the freedom to set their own priorities and make decisions based on their values and preferences concerning their health and healthcare behaviour. They appreciate their GPs 


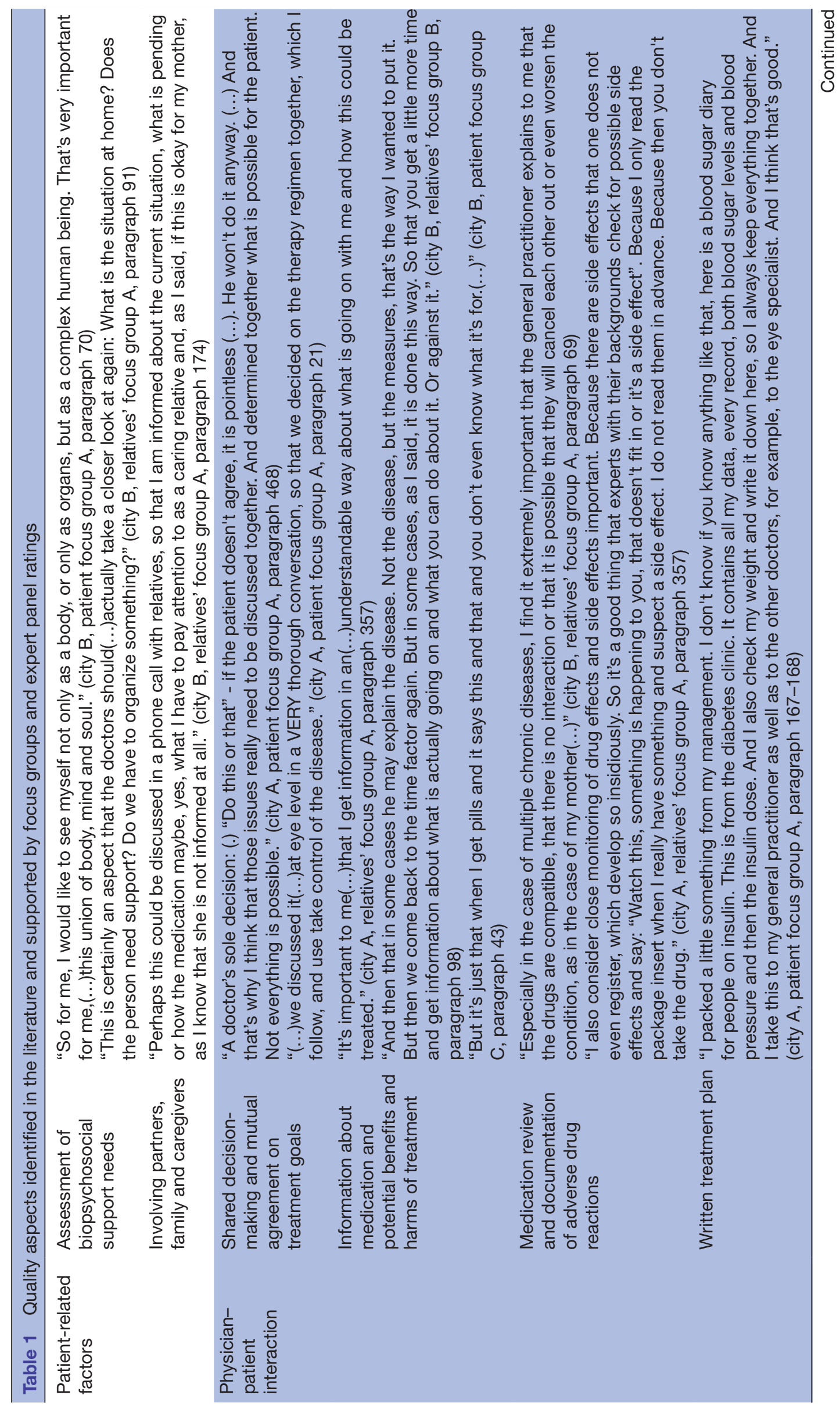




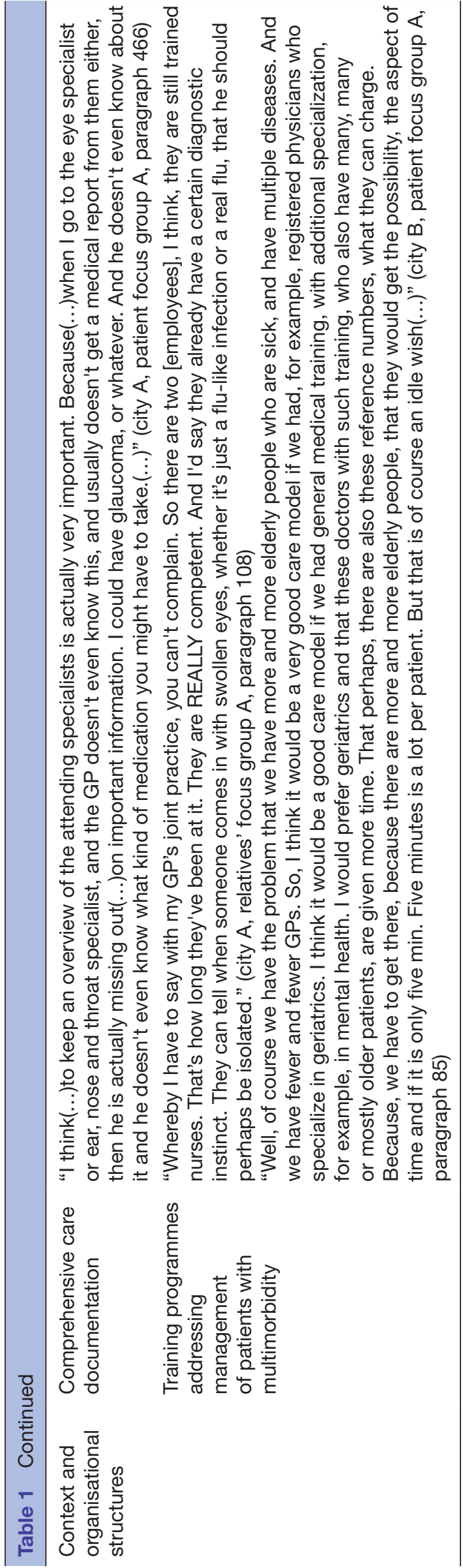

supporting them in this approach and the autonomy this respect gives them.

Information about medication and potential benefits and harms of treatment

Our focus group participants did not differentiate clearly between information and advice on their diagnosis, disease or condition and risks, medications (for example, indication, dosage and interactions), or non-pharmacological treatments and their benefits and potential side effects. They emphasise the importance of detailed and comprehensible information on all these aspects. Either way, some stated not to be interested in very detailed descriptions of potential risks and side effects. The amount of information given must be tailored to the patient's needs even though these consultations might need more time than usually budgeted.

Medication review and documentation of adverse drug reactions Medication reviews are highly acclaimed by the focus group participants. Patients and their relatives wish for the GP to check for interactions regularly especially with medication prescribed by others and over-the-counter drugs. They expressed criticism of the high numbers of prescribed drugs and low engagement of health professionals to actively inquire about drug-related problems and to search for highly tolerable medications. Patients focus less on the thorough documentation of adverse drugs reactions than on their monitoring and handling. They wish for the GP to detect signs of adverse effects and monitor them, for example, through regular follow-ups.

Written treatment plan

Focus group participants recognise the value of written treatment schedules that include overviews on scheduled healthcare appointments plus instructions, for example, whether they have to appear with an empty stomach for bloodwork. They emphasised the advantages of automated recalls systems. Another focus was on recorded treatment protocols, for example, keeping a blood pressure journal or a diabetes log book containing measured values and other relevant parameters. Patients proposed using digital solutions for facilitating care coordination between different providers.

\section{Comprehensive care documentation}

The vast majority of the focus group participants consider comprehensive care documentation as a vital part of highquality care, emphasising importance of the exchange of information on diagnostic testing or examination results and prescribed medication, giving the GP the opportunity to coordinate care and consult the specialist about the patient's treatments. Patients report that the responsibility for this exchange is often in the patients' hand, being the ones to take care of specialists' letters being issued to the GP. Under the premise of data security, patients would support a digital exchange of doctor's letters, but sometimes doubt the 'digital competencies' especially of the older generation of physicians. 
Table 2 Literature-based quality aspects not supported by focus groups

Patient-related factors

interaction

Screening for depression

Proactive pain assessment

Monitoring of pain

management

Addressing financial support needs

Quality of life assessment

Assessment of symptom burden

Establishing patient

preferences

Identification of patients with multimorbidity

Assessment of treatment burden

Monitoring adherence to treatment

Context and organisational structures

Assigning responsibility for coordination of care

Training programmes addressing management of patients with multimorbidity

Patients put emphasis on the competencies of the practice team. For medical assistants this means, for example, being experienced in taking blood samples or administering vaccinations or injectable medications. Another aspect is the ability to triage patients according to the severity and urgency of their treatment needs. GPs should engage in continuous medical education, be up to date on actual research results and technological advances. Participants valued additional training in the field of geriatrics or psychology and proposed regular supervision and peer consultation for complex problems in multimorbid patients.

\section{Literature-based quality aspects not supported by focus groups}

Table 2 gives an overview of quality aspects identified in the literature review and supported by the expert panel but not accounted for in focus groups. As this paper focuses on the focus group result, these quality aspects are described extensively elsewhere (manuscript in preparation).

\section{DISCUSSION}

\section{Main results}

By asking patients with multimorbidity and their relatives in focus groups about their experiences with primary healthcare, we were able to identify important quality aspects from their point of view and derived four new patient-relevant QIs to date not represented in guidelines or the literature on quality of care in multimorbidity. Out of these, two QIs concerning regular updates of written medication plans and patient education and fostering self-management were supported by the expert panel. On the other hand, regular check-ups and GP-coordinated care were not supported by the expert panel. Half of the literature-based QI, for example, assessment of biopsychosocial support needs, establishing patient preferences and shared decision-making, were supported by participants' accounts, while more technical domains regarding assessment and treatment regimens were not covered in the focus groups.

\section{Strength and limitations}

To obtain a comprehensive picture of aspects of quality of care from the affected persons' point of view, we asked not only patients with multimorbidity, but also their relatives (often informal caregivers) in separate groups. Focus group participants were recruited in two very differently structured regions of northern and southern Germany and represent a wide spectrum of combinations of different diseases. We therefore assume that our results might be cautiously generalisable to patients with multimorbidity in primary care all over Germany. However, the experiences reported by patients with multimorbidity and their relatives in the focus groups may to some extent be specific to the German healthcare system. In other countries, such as the UK, for example, medication reviews and the provision of medication information are the responsibility of pharmacists. Our results should not be transferred to other countries without cautious reflection, as the organisation of healthcare systems and the implementation of (primary) care differ between Germany and other countries.

Reflecting and evaluating own experiences are dependent on representation of different perspectives, lived experiences and group interaction, and must be fragmentary, as participants were lay persons regarding healthcare (quality). Therefore, it did not seem feasible to ask the participants to propose QI. Instead, we focused on positive and negative experiences with primary care and derived patient-relevant QI indirectly. As many accounts can be matched to QI derived from the literature and half of the newly developed QIs were supported by expert consensus, this methodology seems to be plausible and practicable.

Although the questions focused on experiences regarding the related patients with multimorbidity, the results from focus groups with relatives show that for some participants it was difficult to focus on their role as (caregiving) relative. Many participants referred to their own healthcare experiences being affected by multiple conditions themselves, which reflects the spectrum of issues and challenges in the field as the prevalence of multimorbidity increases in older age. ${ }^{31}$

Discussion of results and comparison with existing literature The complexities of managing multimorbidity are widely known ${ }^{10}$ and there is a growing amount of literature on interventions for improving outcomes in patients with 
multimorbidity. ${ }^{11}{ }^{32}$ Different approaches to tackle the challenges of caring for patients with multimorbidity were discussed, from the Chronic Care Model, ${ }^{13}$ a systematic collection and review of interventions ${ }^{32}$ and quality standards ${ }^{33}$ to a German meta-algorithm, ${ }^{14}$ but a QI set involving the perspective of affected patients and their (potential) informal caregivers is still missing.

Since 2016, patients enrolled in SHI in Germany have a right to be provided with a recorded medication plan if they are prescribed at least three different long-term medications, which is very much appreciated by persons with multimorbidity in our study and elsewhere. ${ }^{34}$ If patients consent, these data can be saved to the electronic health card or record to allow for a standardised digital exchange of this information of these data between providers. ${ }^{35}$ Despite preferring a written medication plan and stating the problem of insufficient communication between prescribing physicians, participants of our focus groups judged this incorporation ambivalently as they saw problems concerning data safety and confidentiality $^{37}$ as well as (older) GPs' digital literacy.

Patients with multimorbidity wish for patient education, fostering of self-management and periodical check-ups might arise from their experiences with patient education and regular control of, for example, blood values, respiratory function and blood pressure during the structured disease management programmes (DMPs, eg, ${ }^{38}$ ) that many patients with diabetes, COPD or heart failure take part in. DMPs for single diseases and lone-standing selfmanagement interventions for patients with multimorbidity have shown to be helpful $\left(\mathrm{eg}^{39}{ }^{40}\right.$ ), which supports the patient-education QI (see also ${ }^{19}$ ). While a recent systematic review supports the importance of monitoring treatment effects and clinical parameters, ${ }^{11}$ this is no plea for generalised periodical check-ups without a definite indication.

The proposition of a GP-coordinated care was not supported by the expert panel as this care model is not yet sufficiently embedded within routine care in Germany, ${ }^{41}$ although $\$ 73$ SGB V ${ }^{42}$ makes way for general practitionercentred primary care (coordination) since 2003, which is also highlighted in the policy paper of the German College of General Practitioners and Family Physicians from $2012 .{ }^{43}$

Literature-based QIs validated by the focus group focus mostly on aspects that address interpersonal communication, holistic treatment approaches and processes that allow patients to make their own choices based on comprehensive information. This aligns our findings with the wide scientific consensus that the treatment of patients with multimorbidity should be informed by a patient-centred approach. ${ }^{19}{ }^{44-46}$ The majority of the quality statements proposed by the National Institute for Health and Care Excellence ${ }^{33}$ align with the indicators resulting from our study (eg, 'assessing values, priorities and goals', 'care coordination' and 'reviewing medicines and other treatments'). All measurement frameworks seem to have one thing in common: taking shared decision-making into account as central aspect of patient-centred care. ${ }^{47}$

An explanation for the lack of support for the QI dealing with screening and assessment issues in the focus groups might be due to the participants' perspective as individuals and end users of care structures and processes. Qualitative methods are mostly able to elicit patients' personal experiences with and views on healthcare (processes) and lay persons are seldom confronted with meta-level issues directed at groups of patients and not individual patients.

Other projects aiming for the development of quality frameworks in multimorbidity predominantly focused on outcome measurement. ${ }^{4-50}$ Scientific evidence on generic health outcome measures to assess quality of care for patients with multimorbidity is still lacking. In the light of individual goals and priorities of patients with multimorbidity, it proves difficult to define outcome indicators suitable for all. Keeping that in mind, our QI set addressing mainly care processes and covering a broad range of care domains is evidence based and seems to be very adequate for the evaluation of quality of care for patients with multimorbidity.

\section{Future research}

Primary care patients ( $\geq 65$ years) and their GPs will be questioned using standardised patient-reported outcome measures (related to the identified QI) and other instruments (measuring behaviour described in the identified QI) to study validity and applicability of the developed set of QIs. The definite set of QIs will be determined based on the study results.

\section{Practical implications}

The QI set finally developed in the MULTIqual Study can be used as a framework for assessing the quality of care in the German healthcare system. It will facilitate implementation of treatment standards, increase the use of existing guidelines, ${ }^{1451}$ and help to reduce overuse, underuse and misuse of healthcare resources. The QI set will serve as a reference framework for future evaluations of complex interventions and care models for patients with multimorbidity.

\section{CONCLUSION}

Our study has demonstrated that focus groups with patients and their relatives adding important aspects in QI development should be incorporated by default in QI development processes and constitute a reasonable addition to traditional QI development. ${ }^{19}{ }^{20}$ Future challenges lie in the adoption of these quality criteria as practical and valid standardised measures and their implementation in primary care.

\section{Twitter Martin Scherer @degampraesident}

Acknowledgements We would like to thank all patients and their relatives for their time and effort invested in participating in the focus groups, the experts for participating in the expert panel, Tabea Eissing for her contributions to the 
development of the focus group guides and Thomas Kloppe for co-moderating one of the focus groups.

Contributors MS, DL and JSz-acquisition of funding for and conception, design and supervision of the study. AB, KG, NJP and JSc-moderation of focus groups. $\mathrm{AB}, \mathrm{KG}, \mathrm{CH}, \mathrm{NJP}$ and JSC - data analysis and interpretation. NJP-drafting of the manuscript. AB, KG, CH, DL, JSC, JSz and MS—critical revision of former versions and final approval of the manuscript.

Funding This work was supported by the Innovation Fund of the Federal Joint Committee (G-BA; grant no. 01VSF16058).

Competing interests None declared.

\section{Patient consent for publication Not required.}

Ethics approval Ethics approval was obtained from the Ethics Committee of the Hamburg Medical Association, (10 September 2018, PV5846), from the Clinical Ethics Committee Heidelberg (19 December 2018, S-665/2018) and the Medical Association of Baden-Wuerttemberg (13 November, B-F-2018-096).

Provenance and peer review Not commissioned; externally peer reviewed.

Data availability statement No data are available. The data generated and analysed during the current study are not publicly available due to the study's assurances to participants that the full raw focus group data would not be shared publicly, and that all attempts would be made to maintain confidentiality. We named the people who are responsible for data analysis to the focus group participants in the written consent and they did not agree with the sharing of the full raw data.

Supplemental material This content has been supplied by the author(s). It has not been vetted by BMJ Publishing Group Limited (BMJ) and may not have been peer-reviewed. Any opinions or recommendations discussed are solely those of the author(s) and are not endorsed by BMJ. BMJ disclaims all liability and responsibility arising from any reliance placed on the content. Where the content includes any translated material, BMJ does not warrant the accuracy and reliability of the translations (including but not limited to local regulations, clinical guidelines, terminology, drug names and drug dosages), and is not responsible for any error and/or omissions arising from translation and adaptation or otherwise.

Open access This is an open access article distributed in accordance with the Creative Commons Attribution Non Commercial (CC BY-NC 4.0) license, which permits others to distribute, remix, adapt, build upon this work non-commercially, and license their derivative works on different terms, provided the original work is properly cited, appropriate credit is given, any changes made indicated, and the use is non-commercial. See: http://creativecommons.org/licenses/by-nc/4.0/.

\section{ORCID iD}

Nadine Janis Pohontsch http://orcid.org/0000-0002-0966-4087

\section{REFERENCES}

1 Advisory Council on the Assessment of Developments in the Health Care System [Sachverständigenrat zur Begutachtung der Entwicklung im Gesundheitswesen]. Special Report 2009. Coordination and Integration - Health Care in an Aging Society. [Sondergutachten 2009. Koordination und Integration Gesundheitsversorgung in einer Gesellschaft des längeren Lebens.]. Available: https://www.svr-gesundheit.de/fileadmin/Gutachten/ Sondergutachten_2009/Kurzfassung_engl_2009.pdf [Accessed 13 Apr 2021].

2 Marengoni A, Angleman S, Melis R, et al. Aging with multimorbidity: a systematic review of the literature. Ageing Res Rev 2011;10:430-9.

3 France EF, Wyke S, Gunn JM, et al. Multimorbidity in primary care: a systematic review of prospective cohort studies. Br J Gen Pract 2012;62:e297-307.

4 Gijsen R, Hoeymans N, Schellevis FG, et al. Causes and consequences of comorbidity: a review. J Clin Epidemiol 2001;54:661-74.

5 Clyne B, Cooper JA, Hughes CM, et al. 'Potentially inappropriate or specifically appropriate?' Qualitative evaluation of general practitioners views on prescribing, polypharmacy and potentially inappropriate prescribing in older people. BMC Fam Pract 2016;17:109.

6 Koller D, Schön G, Schäfer I, et al. Multimorbidity and long-term care dependency--a five-year follow-up. BMC Geriatr 2014;14:70.

7 van den Bussche $\mathrm{H}$, Kaduszkiewicz H, Schäfer I, et al. Overutilization of ambulatory medical care in the elderly German population?-An empirical study based on national insurance claims data and a review of foreign studies. BMC Health Serv Res 2016;16:129.
8 Jin H, Tang C, Wei Q, et al. Age-related differences in factors associated with the underuse of recommended medications in acute coronary syndrome patients at least one year after hospital discharge. BMC Cardiovasc Disord 2014;14:127.

9 Sönnichsen A, Trampisch US, Rieckert A, et al. Polypharmacy in chronic diseases-Reduction of inappropriate medication and adverse drug events in older populations by electronic decision support (PRIMA-eDS): study protocol for a randomized controlled trial. Trials 2016;17:57.

10 Wallace E, Salisbury C, Guthrie B, et al. Managing patients with multimorbidity in primary care. BMJ 2015;350:h176.

11 Muth C, Blom JW, Smith SM, et al. Evidence supporting the best clinical management of patients with multimorbidity and polypharmacy: a systematic guideline review and expert consensus. J Intern Med 2019;285:272-88.

12 Bodenheimer T, Wagner EH, Grumbach K. Improving primary care for patients with chronic illness. JAMA 2002;288:288.

13 Bodenheimer T, Wagner EH, Grumbach K. Improving primary care for patients with chronic illness: the chronic care model, part 2. JAMA 2002;288:288.

14 German College of General Practitioners and Family Physicians [DEGAM]. Guideline Multimorbidity [Leitlinie Multimorbidität]. Available: http://www.degam.de/degam-leitlinien-379.html [Accessed 13 Apr 2021].

15 Federal Ministry of Health [Bundesministerium für Gesundheit]. Available: https://www.bundesgesundheitsministerium.de/fileadmin/ Dateien/5_Publikationen/Gesundheit/Broschueren/200629_BMG_ Das_deutsche_Gesundheitssystem_EN.pdf [Accessed 13 Apr 2021].

16 National Association of Statutory Health Insurance Physicians [Kassenärztliche Bundesvereinigung]. Available: https://www.kbv. $\mathrm{de} / \mathrm{media} / \mathrm{sp} /$ Gesamt_Systeme_Installationen.pdf [Accessed $13 \mathrm{Apr}$ 2021].

17 Herzberg H, Bernateck K, Welti F. Patient Participation in Development of Quality Indicators using the Example of National Disease Management Guidelines for Chronic Heart Failure - A Qualitative Analysis of Collective Perspectives [Patientenbeteiligung bei der Entwicklung von Qualitätsindikatoren am Beispiel der Nationalen VersorgungsLeitlinie Chronische Herzinsuffizienz - Eine qualitative Analyse kollektiver Sichtweisen]. Gesundheitswesen 2016;78:373-7.

18 Valderas JM, Gangannagaripalli J, Nolte E, et al. Quality of care assessment for people with multimorbidity. J Intern Med 2019;285:289-300.

19 Pohontsch NJ, Herzberg H, Joos S, et al. The professional perspective on patient involvement in the development of quality indicators: a qualitative analysis using the example of chronic hear failure in the German health care setting. Patient Prefer Adherence 2015;9:151-9.

20 Kötter T, Schaefer FA, Scherer M, et al. Involving patients in quality indicator development - a systematic review. Patient Prefer Adherence 2013;7:259-68.

21 Kötter T, Blozik E, Scherer M. Methods for the guideline-based development of quality indicators--a systematic review. Implement Sci 2012;7:21.

22 Campbell SM, Shield T, Rogers A, et al. How do stakeholder groups vary in a Delphi technique about primary mental health care and what factors influence their ratings? Qual Saf Health Care 2004;13:428-34.

23 Baudendistel I, Noest S, Peters-Klimm F, et al. Bridging the gap between patient needs and quality indicators: a qualitative study with chronic heart failure patients. Patient Prefer Adherence 2015;9:1397-405.

24 Tong A, Sainsbury P, Craig J. Consolidated criteria for reporting qualitative research (COREQ): a 32-item checklist for interviews and focus groups. Int J Qual Health Care 2007;19:349-57.

25 Sofaer S, Firminger K. Patient perceptions of the quality of health services. Annu Rev Public Health 2005;26:513-59.

26 Bahadori M, Yaghoubi M, Haghgoshyie E. Patients' and physicians' perspectives and experiences on the quality of medical consultations: a qualitative study. JBI Evid Implement 2020;18:247-55

27 Pohl H. Evaluating quality in endoscopy. Endoscopy 2017;49:581-7.

28 Kuckartz U. Qualitative Content Analysis [Qualitative Inhaltsanalyse. 1st ed. Beltz Juventa, 2012.

29 Potter J, Wetherell M. Discourse and social psychology: beyond attitudes and behaviour. London: Sage, 1987.

30 Steinke I. Quality Criteria in Qualitative Research. In: Flick U, von Kardorff E, Steinke I, eds. A companion to qualitative research. London: Sage, 2004: 184-90.

31 Polenick CA, Leggett AN, Webster NJ, et al. Multiple chronic conditions in spousal caregivers of older adults with functional 
disability: associations with caregiving difficulties and gains. $J$ Gerontol B Psychol Sci Soc Sci 2020;75:160-72.

32 Smith SM, Wallace E, O'Dowd T, et al. Interventions for improving outcomes in patients with multimorbidity in primary care and community settings. Cochrane Database Syst Rev 2016;9.

33 National Institute for Health and Care Excellence (NICE). Multimorbidity quality standard, 2017. Available: https://www.nice. org.uk/guidance/qs153 [Accessed 13 Apr 2021].

34 Botermann L, Krueger K, Eickhoff C, et al. Patients' handling of a standardized medication plan: a pilot study and method development. Patient Prefer Adherence 2016;10:621-30.

35 Klein S, Schellhammer S, et al. Medication Infrastructure Development in Germany. In: Aanestad M, Grisot M, Hanseth O, eds. Information Infrastructures within European health care. Cham: Springer, 2017.

36 National Association of Statutory Health Insurance Physicians [Kassenärztliche Bundesvereinigung]. Medication plan [Medikationsplan]. Available: https://www.kbv.de/html/ medikationsplan.php [Accessed 13 Apr 2021].

37 Dietzel GTW. From eEurope 2002 to the electronic health card: Chances for the Health Care System [Von eEurope 2002 zur elektronischen Gesundheitskarte: Chancen für das Gesundheitswesen]. Dtsch Arzteb/ 2002:99:A 1417-9.

38 Fuchs S, Henschke C, Blümel M, et al. Disease management programs for type 2 diabetes in Germany: a systematic literature review evaluating effectiveness. Dtsch Arztebl Int 2014;111:453-63.

39 Mehring M, Donnachie E, Fexer J, et al. Disease management programs for patients with COPD in Germany: a longitudinal evaluation of routinely collected patient records. Respir Care 2014:59:1123-32.

40 Contant Éric, Loignon C, Bouhali T, et al. A multidisciplinary selfmanagement intervention among patients with multimorbidity and the impact of socioeconomic factors on results. BMC Fam Pract 2019;20:53.
41 Lübeck R, Beyer M, Gerlach F. Rationale und Stand der hausarztzentrierten Versorgung in Deutschland [Rationale and dissemination of "GP centered health care" ("HzV") in Germany]. Bundesgesundheitsblatt Gesundheitsforschung Gesundheitsschutz 2015;58:360-6.

42 SGB V Gesetzliche Krankenversicherung - SGB V Sozialgesetzbuch. Available: https://www.sozialgesetzbuch-sgb.de/sgbv/1.html [Accessed 13 Apr 2021].

43 German College of General Practitioners and Family Physicians [DEGAM]. General Practice - Focused on the Whole Person [Allgemeinmedizin - spezialisiert auf den ganzen Menschen], 2012. Available: http://www.degam.de/files/Inhalte/Degam-Inhalte/ Ueber uns/Positionspapiere/DEGAM-Position_Paper_on_the_Future.pdf [Accessed 13 Apr 2021].

44 Boyd CM, Lucas GM. Patient-centered care for people living with multimorbidity. Curr Opin HIV AIDS 2014;9:419-27.

45 Schattner A, Bronstein A, Jellin N. Information and shared decisionmaking are top patients' priorities. BMC Health Serv Res 2006;6:21.

46 Kvåle K, Bondevik M. What is important for patient centred care? A qualitative study about the perceptions of patients with cancer. Scand J Caring Sci 2008;22:582-9.

47 Godolphin W. Shared decision-making. Healthc Q 2009;12:e186-90.

48 Working Group on Health Outcomes for Older Persons with Multiple Chronic Conditions. Universal health outcome measures for older persons with multiple chronic conditions. J Am Geriatr Soc 2012;60:2333-41.

49 National Quality Forum (NQF). Multiple chronic conditions measurement framework. Available: https://www.qualityforum.org/ Publications/2012/05/MCC_Measurement_Framework_Final_Report. aspx [Accessed 13 Apr 2021].

50 Akpan A, Roberts C, Bandeen-Roche K, et al. Standard set of health outcome measures for older persons. BMC Geriatr 2018;18:36.

51 Grimshaw JM, Thomas RE, MacLennan G, et al. Effectiveness and efficiency of guideline dissemination and implementation strategies. Health Technol Assess 2004;8:iii-iv. 1-72. 